Journal of Engineering and Applied Sciences 14 (Special Issue 4): 7325-7328, 2019

ISSN: 1816-949X

(C) Medwell Journals, 2019

\title{
Nonlinear Optical Properties and Optical Limiting of Ag Nanoparticle Prepared by Laser Ablation
}

\author{
Jassim Mohamad Jassim, Qussay Mohamad Salman and Haneen Jawad Kadom \\ College of Science for Women, University of Babylon, Hillah, Iraq \\ aljwaryhaneen@gmail.com
}

\begin{abstract}
In this research have been studied linear properties (absorption coefficient, reflective index, bandwidth, absorption spectra) and nonlinear properties nanoparticle Ag-NP which prepared by laser ablation with $(50,100,150)$ in distal water. The results of linear properties show that the maximum absorption wavelength $\left(\lambda_{\max }\right)$ has a shift toward long wavelengths with increasing in concentration also the bandwidth, refractive index and linear absorption coefficient have been calculated while the result of nonlinear properties show that open aperture Z-scan measurements at wavelength $532 \mathrm{~nm}$ for Ag-NPs show the nonlinear absorption coefficient is positive (defocusing) exhibited as $\beta=(29.094 \times 10-3) \mathrm{cm} / \mathrm{w}$ for 150 pulses which confirm Revers Saturated Absorption (RSA) and we obtund the close aperture Z-scan measurements show the nonlinear refractive index is negative (self-defocusing) that $\mathrm{n}_{2}=(4.0539 \times 10-7) \mathrm{cm}^{2} / \mathrm{w}$ for $150 \mathrm{p}$ is the optical limiting measurements for silver nano-particle (Ag-NPs) occur at $(4.14 \mathrm{~mW})$ while the limiting Power $\left(\mathrm{P}_{\mathrm{L}}\right)$ for silver nano-particle $(\mathrm{Ag}-\mathrm{NPs})$ occur at $(4.16 \mathrm{~mW})$ for liquid media.
\end{abstract}

Key words: Nano-scale materials, silver nanoparticles, nonlinear absorption, nonlinear scattering, optical limiter, refractive

\section{INTRODUCTION}

Rapid technological advancements in optics have placed great demand on the development of Nonlinear Optical (NLO) materials with prominent applications in optical limiting and all optical switching (Venkatram et al., 2008; Huang et al., 2008; George et al., 2008). Extremely large number of organic compounds with delocalized electron and conjugated double bond systems and a large dipole moment have been synthesized to realize the susceptibilities far larger than the inorganic optical materials (Mallik and Kar, 2005). Z-scan technique (Sheik-Bahae et al., 1989) based on the spatial distortion of a laser beam passed through a NLO material is widely used in material characterization because of its simplicity, high sensitivity and well elaborated theory. The opportunity to conduct simultaneous measurements of various NLO parameters in one set of experiments also makes this technique attractive and applicable for different materials. This method yields both the sign and the magnitude of the nonlinearity and the value of a minimum of analysis (Przhonska et al., 1998; Wang et al., 1994; Geethakrishnan and Palanisamy, 2007). Z-scan studies also yield important information regarding the response time and the dynamics of the transient processes contributing to the nonlinear refractive index (Sinha et al., 2000).

\section{MATERIALS AND METHODS}

The samples of Ag-NPs have been prepared by using laser ablation or photo ablation which is the process of take off material from a solid (or occasionally liquid) surface by rise it with a laser beam. At fading laser flux, the material is heated by the absorbed laser energy and steam https://en.wikipedia.org/wiki/Evaporation or sublimates. At high laser flux, the material is typically modify to a plasma. Usually, laser ablation refers to removing material with a pulsed laser but it is likely to ablate material with a persistent wave laser beam, if the laser intensity is high enough. The kind of laser was used for laser ablation: Q-switch Nd-YAG laser type Huafei providing pulses of $(532 \mathrm{~nm})$ wavelength with a maximum energy per pulse of $(80 \mathrm{~mJ})$, pulse width of $(10 \mathrm{nsec})$ with number of pulses $(50,100,150)$, repetition rate of $(6 \mathrm{~Hz})$ and effective beam diameter of $5 \mathrm{~mm}$. The laser beam was focused by using a lens $(15 \mathrm{~cm})$ focal length onto a metallic target. The metallic target was fixed by a fixture inside the vial and immersed at $(3 \mathrm{~mm})$ depth in the

Corresponding Author: Jassim Mohamad Jassim, College of Science for Women, University of Babylon, Hillah, Iraq aljwaryhaneen@gmail.com 


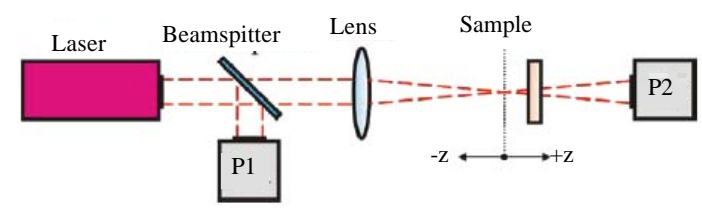

Fig. 1: System of a standard open-aperture Z-scan setup in which the transmittance coefficient of the sample $(\mathrm{P} 2 / \mathrm{P} 1)$ is measured as a function of sample position z. $\mathrm{z}=0$ agrees to the position of the focal point in the center of the sample

solution inside the vial the ablation process was typically achieved at room temperature. The spectra absorption of samples have been measured by using UV-Vis spectrophotometer was used to measure the absorption spectraum for solution and films, it is produce by Optima, Japan, Aquarius (7000) with laboratories in the part of Physics in the College of Science for Women, University of Babylon.

Z-scan measurements were perfect in the work both two common parts, closed and open aperture. Each section was employed at $532 \mathrm{~nm}$ at different power, the closed aperture Z-scan was utilize to measure the nonlinear refractive index while the open-aperture was used to measure the nonlinear absorption coefficient by using laser SHG of CW (Nd-YAG). The set-up arrange as shown in Fig. 1.

The mean part of $\mathrm{Z}$-scan technique wich used in this research pumping by laser diode (Nd-YAG) laser at wavelength $532 \mathrm{~nm}$ at power $(20 \mathrm{~mW})$, the focal length of lens is $10 \mathrm{~cm}$, the power meter is measurement of wavelengths from 400-1100 nm, produce by mobiken type (LP1) Japanese origin and digital type.

\section{RESULTS AND DISCUSSION}

The absorption spectrum of Ag-NPs samples is shown in Fig. 2, the increase intensity of absorption with the increased concentration is due to the increased number of molecules which in turn to increases the probability of absorption with the concentrations used this agrees with Beer-Lambert Law. The peaks of absorption spectrum shifted toward the longer wavelengths (Red shift) when the concentration increased because of the dipole moment of the blustery state is higher than the lower state. The nonlinear refractive index of the silver nanoparticles (Ag-NPs) were calculate by closed Z-scan method, the linear transmission (s) was found to be $(0.3)$, the normalized Transmittance $T_{p-v}$ of dye in liquid media at different pulses of number $(50,100$ and 150$)$ pulses $/ \mathrm{s}$ are shown in Fig. 3 and 4, respectively. This peak-valley

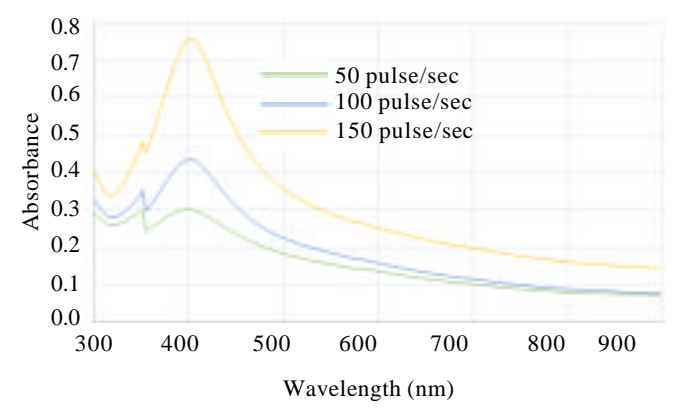

Fig. 2: Absorption spectrum for (Ag-NPs)

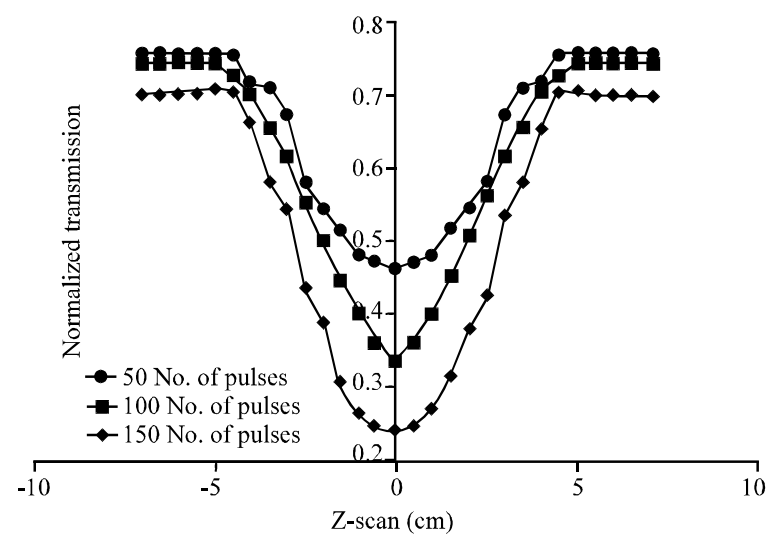

Fig. 3: Close aperture Z-scan for Ag-NPs in distilled water (liquid media) at different pulses for power $(20 \mathrm{~mW})$ at $(532 \mathrm{~nm})$

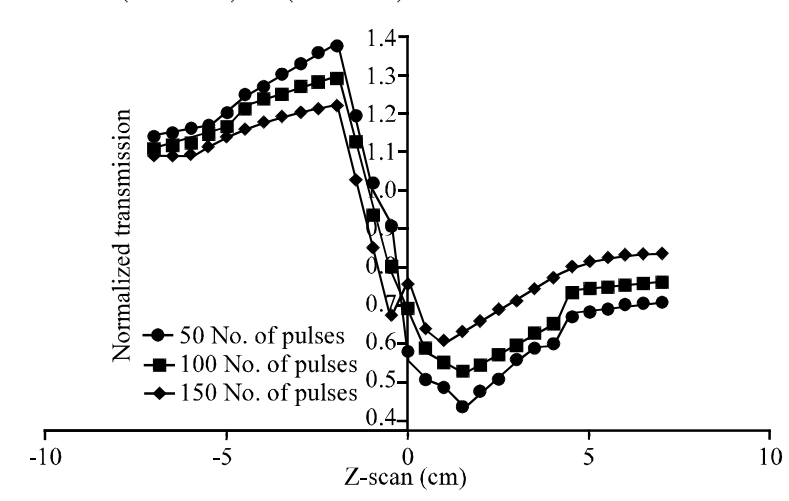

Fig. 4: Open aperture Z-scan for Ag-NPs in distilled water $=($ Liquid media) at different pulses for power $(20 \mathrm{~mW})$ at $(532 \mathrm{~nm})$

normalized Transmittance $\left(T_{p-v}\right)$ mark indicates the self defocusing (positive lensing) stuff and it is represented by positive nonlinear refractive index $\left(\mathrm{n}_{2}\right)$. The experiment is repeated for open aperture $(\mathrm{s}=1)$ to calculate $(\beta)$. Figure 2 and 3 were draw between the sample position and the normalized transmittance, we observed for all the concentrations decrease in transmittance at the focus, 
Table 1: The nonlinear properties of Ag-NPs in distal water in liquid media at different pulses

\begin{tabular}{lllllll}
\hline No. of pulses & $\mathrm{L}_{\text {eff }}(\mathrm{cm})$ & $\mathrm{T}_{\mathrm{ny}}$ & $\Delta \mathrm{T}$ & $\Delta \phi_{0}$ & $\mathrm{n}^{2}\left(\mathrm{~cm}^{2} / \mathrm{w}\right)$ & $\beta(\mathrm{cm} / \mathrm{w})$ \\
\hline 50 & 0.0011 & 0.62 & 0.30 & 1.671 & $2.6457 \times 10^{7}$ & $12.805 \times 10^{-3}$ \\
100 & 0.0011 & 0.75 & 0.45 & 2.021 & $3.2004 \times 10^{7}$ & $23.804 \times 10^{-3}$ \\
150 & 0.0011 & 0.95 & 0.55 & 2.560 & $4.0539 \times 10^{7}$ & $29.094 \times 10^{-3}$ \\
\hline
\end{tabular}

Table 2: Threshold and limiting power for (Ag- NPs) at different pulse in liquid media

\begin{tabular}{lcc}
\hline & Liquid media & \\
& -------- & $\mathrm{P}_{\mathrm{L}}(\mathrm{mW})$ \\
\hline 50 & $\mathrm{P}_{\mathrm{hh}}(\mathrm{mW})$ & 4.39 \\
100 & 4.34 & 4.28 \\
150 & 4.42 & 4.16 \\
\hline
\end{tabular}

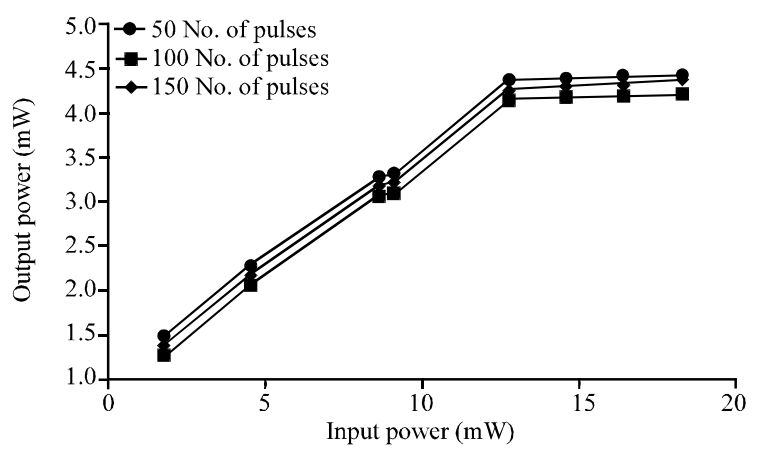

Fig. 5: Threshold and limiting power for (Ag-NPs) at different pulses (liquid media)

it indication the occurrence of SA process in the dye the $T_{p-v}$ and $T_{m}$ are measured and there the $n_{2}, \beta$ are calculated and there values are given in Table 1 to liquid median and film media we observed the value of $\left(n_{2}\right)$ is increase with increase in concentrations, so, the value it is higher than liquid media, this attributed to number of molecules increase with increase in concentration, resulting in enhancement of the third order optical nonlinearity.

The optical limiting effects was studied for silver nano-partical (Ag-NPs) as liquid media at different pulses of $(50,100$ and 150). From Fig. 5, we observed that the output power vary linearly with the input power low input power but found the deviate is starts at high input power this point it is defined threshold Power $\left(\mathrm{P}_{\mathrm{th}}\right)$, reaches a saturated point this point is defined the limiting Power $\left(\mathrm{P}_{\mathrm{L}}\right)$ because the non-linear absorption coefficient it is increase with increase incident power. The $\mathrm{P}_{\text {th }}$ and $\mathrm{P}_{\mathrm{L}}$ are measured and there values are given in Table 2 . We observed the limiting power (and threshold power are decrease with increase the number of pulses.

\section{CONCLUSION}

In this research we have studied linear properties (absorption coefficient, reflective index, bandwidth, absorption spectra and nonlinear properties (nonlinear absorption coefficient $(\beta)$, nonlinear refractive index $\left(\mathrm{n}_{2}\right)$ of Ag-NPs for at different concentration, the results show. Open aperture Z-scan measurements for silver nano-particle (Ag-NPs) liquid media show the nonlinear absorption coefficient $(\beta)$ is positive which confirm revers saturated absorption and Z-scan close measurements show that the nonlinear refractive index is negative (self-defocusing). The limiting power for silver nano-particle (Ag-NPs) occur at $4.14 \mathrm{~mW}$ for liquid media. The threshold and limiting power decreases with increasing the nanoparticle concentration.

\section{REFERENCES}

Geethakrishnan, T. and P.K. Palanisamy, 2007. Z-scan determination of the third-order optical nonlinearity of a triphenylmethane dye using $633 \mathrm{~nm} \mathrm{He}-\mathrm{Ne}$ laser. Opt. Commun., 270: 424-428.

George, M., C.I. Muneera, C.P. Singh, K.S. Bindra and S.M. Oak, 2008. Z-scan studies and optical limiting of nanosecond laser pulses in neutral red dye. Opt. Laser Technol., 40: 373-378.

Huang, T., Z. Hao, H. Gong, Z. Liu and S. Xiao et al., 2008. Third-order nonlinear optical properties of a new copper coordination compound: A promising candidate for all-optical switching. Chem. Phys. Lett., 451: 213-217.

Mallik, T. and T. Kar, 2005. Growth and characterization of nonlinear optical L-arginine dihydrate single crystals. J. Crystal Growth, 285: 178-182.

Przhonska, O.V., J.H. Lim, D.J. Hagan, E.W. Van Stryland and M.V. Bondar et al., 1998. Nonlinear light absorption of polymethine dyes in liquid and solid media. J. Opt. Soc. Am. B., 15: 802-809.

Sheik-Bahae, M., A.A. Said and E.W. Van Stryland, 1989. High-sensitivity, single-beam n2 measurements. Opt. Lett., 14: 955-957.

Sheik-Bahae, M., A.A. Said, T.H. Wei, D.J. Hagan and E.W. Van Stryland, 1990. Sensitive measurement of optical nonlinearities using a single beam. IEEE. J. Quant. Elect., 26: 760-769.

Sinha, S., A. Ray and K. Dasgupta, 2000. Solvent dependent nonlinear refraction in organic dye solution. J. Appl. Phys., 87: 3222-3226. 

Venkatram, N., D. NarayanaRao, L. Giribabu and S.
VenugopalRao, 2008. Femtosecond nonlinear optical properties of alkoxy phthalocyanines at $800 \mathrm{~nm}$ studied using Z-scan technique. Chem. Phys. Lett., 464: 211-215.
Wang, J., M. Sheik-Bahae, A.A. Said, D.J. Hagan and E.W. van Stryland, 1994. Time-resolved Z-scan measurements of optical nonlinearities. J. Opt. Soc. Am. B, 11: 1009-1017. 